\title{
Archaeological, archaeomagnetic and thermoluminescence investigation of a baked clay kiln excavated at Chieri, northern Italy: contribution to the rescue of our cultural heritage
} \author{
Alessandro Re ${ }^{3}$, Federico Barello ${ }^{6}$, Silvia Vella ${ }^{5}$, Luigi Cirillo ${ }^{3}$, Monica Gulmini ${ }^{7}$ \\ ${ }^{1}$ Università degli Studi di Torino, Dipartimento di Scienze della Terra, Torino, Italy \\ ${ }^{2}$ ALP-Alpine Laboratory of Palaeomagnetism, Peveragno, Italy \\ ${ }^{3}$ Università degli Studi di Torino, Dipartimento di Fisica, and INFN Torino, Torino, Italy \\ ${ }^{4}$ TecnArt Srl., Università degli Studi di Torino, Torino, Italy \\ ${ }^{5}$ INRIM - Istituto Nazionale di Ricerca Metrologica, Torino, Italy \\ ${ }^{6}$ Soprintendenza per i Beni Archeologici del Piemonte e Museo Antichità Egizie, Torino, Italy \\ ${ }^{7}$ Università degli Studi di Torino, Dipartimento di Chimica, Torino, Italy
}

Evdokia Tema ${ }^{1,2, *}$, Fulvio Fantino ${ }^{3,4}$, Enzo Ferrara $^{5}$, Silvia Allegretti ${ }^{3}$, Alessandro Lo Giudice ${ }^{3}$,

\author{
Article history \\ Received June 23, 2014; accepted September 24, 2014. \\ Subject classification: \\ Dating, Archaeomagnetism, Thermoluminescence, Baked clay, Cultural heritage.
}

\begin{abstract}
Combining different dating techniques is fundamental to constrain the ages of archaeological findings, mainly when direct evidences for their chronological context are not available. This paper presents the results of a combined archaeological, archaeomagnetic and thermoluminescence study of a kiln discovered during a rescue excavation at Chieri, northern Italy. The archaeological site is quite complex mainly due to the interposition of different stratigraphic levels that span from Roman times to present day. The studied kiln belongs to the post-medieval stratigraphic level but the lack of datable diagnostic objects strongly limits the possibility of its accurate dating only by means of archaeological evidences. Archaeomagnetic study was performed on 26 baked clay samples, isolating stable characteristic remanent magnetizations. The statistic comparison of the averaged direction with reference secular variation curves suggests two possible dating intervals. Independent dating from thermoluminescence study of 2 samples is consistent with the second time interval proposed by archaeomagnetism, suggesting that the kiln was abandoned at the beginning of the 17th century. The successful combination of the two independent laboratory techniques provides accurate dating of archaeological baked clays and can be used as routine for future archaeological investigations of rescue excavations.
\end{abstract}

\section{Introduction}

During last decades, the number and the variability of scientific laboratory techniques applied for the investigation of archaeological finds have been significantly increased and nowadays the natural sciences offer valu- able and well-established tools for better understanding the traces of our past. This process is particularly important in the cases where the findings do not include ceramics or other date diagnostic objects. Obtaining as much information as possible, including precise dating of an archaeological site, is even more significant nowadays, since the rapid expansion of new constructions inevitably involves the destruction of archaeological structures in urban areas, often even unearthed, causing the loss of important knowledge about the past. In the case of such excavations, usually called rescue excavations, scientific techniques such as archaeomagnetic and thermoluminescence dating can offer information about the last firing of baked clay material and contribute to the chronological reconstruction of the studied archaeological sites [Liritzis and Thomas 1980, Becker et al. 1994, Schnepp et al. 2003, Tema et al. 2013]. Such information is very important for the evaluation of our cultural heritage and better understanding of our past.

Archaeomagnetic and thermoluminescence (TL) dating present the advantage that both can be applied to the same materials (e.g. kilns, bricks, pottery) and date the same event (last heating of the material). Archaeomagnetism is based on the fact that baked clay archaeological artefacts contain magnetic particles that, when heated and cooled in the presence of the Earth's magnetic field, acquire a thermal remanent magnetiza- 

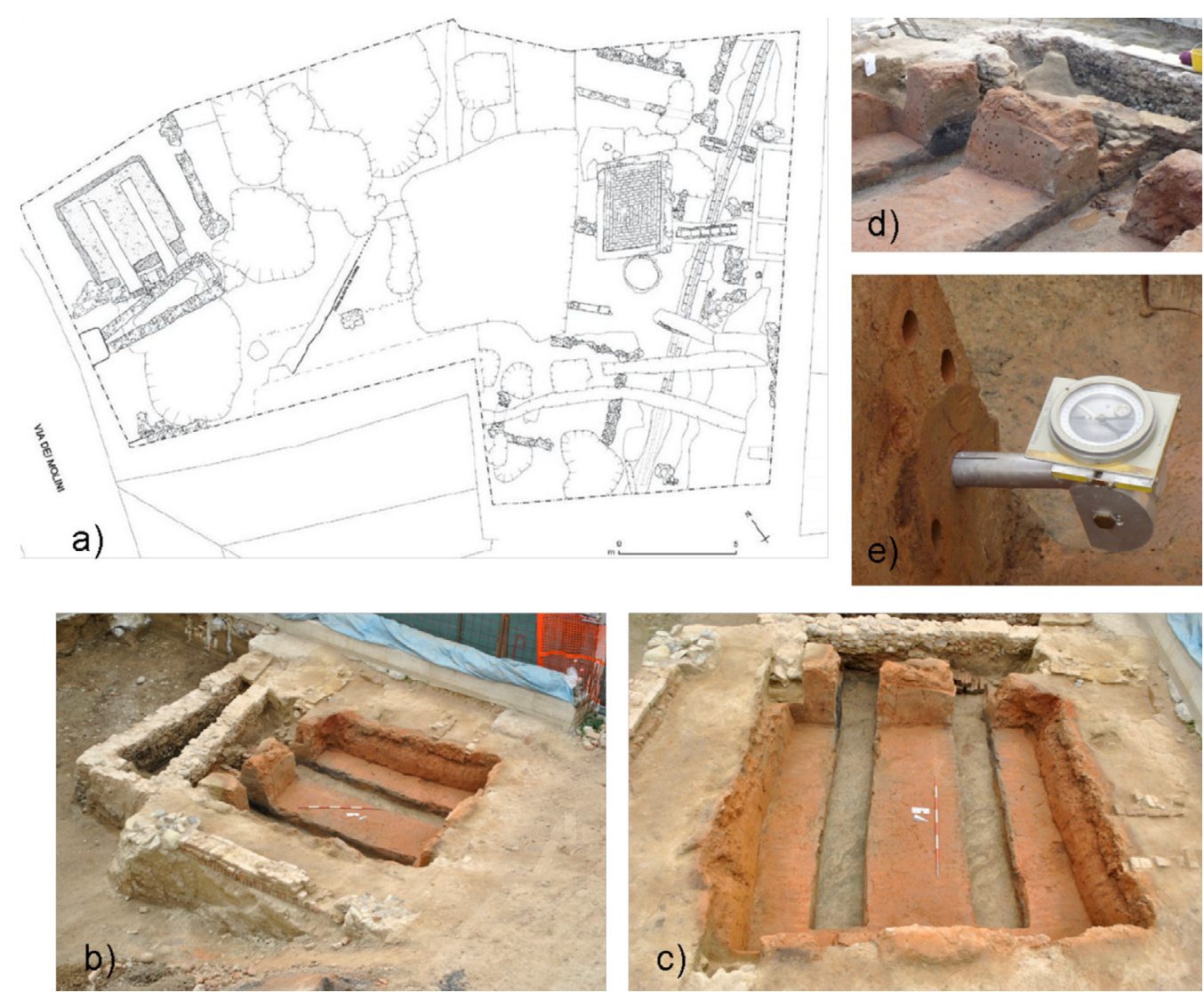

Figure 1. (a) General planimetry of the archaeological site excavated in via dei Molini, Chieri; (b-d) photos of the studied kiln; (e) in situ orientation of the collected samples for archaeomagnetic dating.

tion (TRM) with direction parallel to the local field. Archaeomagnetic dating can be obtained after comparison of the remanent magnetization measured on the undisturbed archaeological artefacts with reference secular variation (SV) curves. Similarly, TL dating is based on the light emission that occurs from the sample when the charges trapped in structural defects within the crystal lattice of several common minerals, such as quartz and feldspar, are thermally annealed. TL enables the evaluation of the time elapsed since mineral grains that carry the entrapped charges were last exposed to daylight or heated (at least $400^{\circ} \mathrm{C}$ ), as in the case of the heating of a kiln during its last use.

This paper presents the results of a combined archaeological, archaeomagnetic and thermoluminescence dating of a baked clay kiln discovered during a rescue excavation at Chieri, northern Italy. Results obtained from the different techniques are compared and used for dating the last use of the kiln. This combined approach highlights the potential of archaeomagnetic and thermoluminescence techniques on dating baked clay archaeological artefacts and the importance of multidisciplinary studies for the rescue of our cultural heritage.

\section{Site context and archaeological time constrains}

The studied kiln was discovered during a rescue excavation for the construction of a modern residential complex at Chieri, via dei Molini $4\left(45^{\circ} 0^{\prime} \mathrm{N}, 07^{\circ} 49^{\prime} \mathrm{E}\right)$, Torino Province, northern Italy. The planimetry of the excavation (Figure 1a) is quite complicated because of the interposition of several structures with ages varying from Roman times to present day. The most important evidences of the Roman period can be found at the southeastern sector of the excavation, comprising several walls oriented from north-east to south-west, that were probably part of ancient residential buildings situated in the western limit of the Roman town called Karreum Potentia. Other residential levels from few centuries ago were also recognised in the site [Barello et al. 2013].

The remains of the studied kiln were found in the north-western part of the excavation. The kiln belongs to the post-medieval stratigraphic level, just few centimetres beneath the present-day surface. Only the lower part of the combustion chamber is preserved, excavated in a clay layer that covers Roman age deposits [Barello et al. 2013]. The combustion chamber is roughly squared $(3.7 \times 3.8 \mathrm{~m}$; with a maximum height of 0.9 $\mathrm{m})$ and the walls were made by clay, which was baked and consolidated due to the repeated exposition to heat during the use of the kiln. Two long feeding channels are recognised, at a distance of about $1.2 \mathrm{~m}$ from each other (Figure 1b,c). The channels were filled with ash, carbonaceous deposits and wooden trash, probably residues of the kiln's last combustion. The use of the 
kiln is not yet well known. Archaeological evidence suggests that it was probably used for the production of bricks. In fact, imprints of bricks are visible on the bottom of the chamber, indicating that the clay blocks to be baked were probably stacked directly on the floor by head and/or edge, arranged on parallel rows oriented from north to south (at least six), plus a single row oriented from west to east along the northern wall. Little information about the age of the kiln is available. Its stratigraphic position suggests a medieval chronology as several post-medieval to modern structures cut the kiln. These structures could likely belong to modern buildings with frontage in the today's Via dei Molini [Barello et al. 2013]. The studied kiln also presents structural features similar to two other kilns excavated in the wider area: one found in via Tana (Chieri) next to the Renaissance walls and possibly used for their construction [Pantò and Vaschetti 2010] and one excavated at Cerrione (near Biella, about $40 \mathrm{~km}$ north of Chieri) which can be dated around 1600-1700 AD, as suggested by the dimensions of the bricks employed for its construction [Spagnolo Garzoli and Barberis 2012]. Nevertheless, the sporadic ceramic findings and the lack of diagnostic objects strongly limit the possibility of accurately dating the kiln by means of archaeological evidence.

\section{Archaeomagnetic dating}

\subsection{Archaeomagnetic sampling}

For archaeomagnetic dating, cylindrical samples were collected with a portable rock driller. Samples were taken from the west and southern walls of the kiln (Figure 1d); we also tried to collect material from the kiln's floor but the clay was not consistent enough and all but one core were broken during drilling. A total of 26 baked clay cores were collected and all of them were independently oriented in situ with a magnetic compass

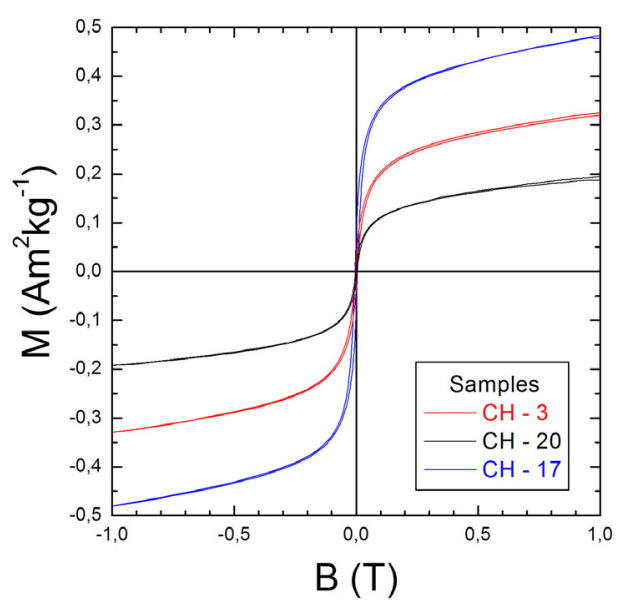

and an inclinometer (Figure 1e). In addition, some nonoriented samples were collected in order to perform rock magnetic analysis and TL dating. Few days after the sampling, the site was destroyed to let the pending project of the new building construction to proceed at the place of the archaeological excavation.

\subsection{Magnetic mineralogy}

The magnetic properties of representative samples have been investigated by isothermal remanent magnetization (IRM) acquisition and back field curves, thermal demagnetization of three IRM components [Lowrie 1990] and hysteresis loops. The IRM acquisition and back field curves were investigated at the ALP Palaeomagnetic laboratory (Peveragno, Italy) using an ASC pulse magnetizer to impart the IRM, applying stepwise increasing magnetic fields up to $1.6 \mathrm{~T}$, and a JR6 spinner magnetometer (AGICO) to measure the remanent magnetization. A three axis IRM was also induced along the three orthogonal axes of the sample, applying first the maximum field (1.6 T) along the $Z$-axis, then an intermediate field $(0.5 \mathrm{~T})$ along the $\mathrm{Y}$-axis and finally a minimum field $(0.1 \mathrm{~T})$ along the $\mathrm{X}$-axis [Lowrie 1990]. The composite three axes IRM was subsequently thermally stepwise demagnetized with a TSD-2 Schonstedt furnace.

Hysteresis loops were obtained at INRIM (Torino, Italy) using a Lake Shore 7400 Vibrating Sample Magnetometer (VSM). $20 \mathrm{mg}$ to $50 \mathrm{mg}$ clay samples were prepared, extracting material from the larger cylindrical samples. The clayey samples underwent magnetization cycles up to a maximum applied field of $1 \mathrm{~T}$. The hysteresis cycles (Figure 2) show two major ensembles of magnetic contributions: 1) magnetite/Ti-magnetite type cycles (e.g. samples $\mathrm{CH}-3, \mathrm{CH}-17, \mathrm{CH}-20$ ), with single domain (SD) and pseudo single domain (PSD) ferrimagnetic particles, together with a minor paramagnetic contribution; 2) faint SD and PSD ferrimag-

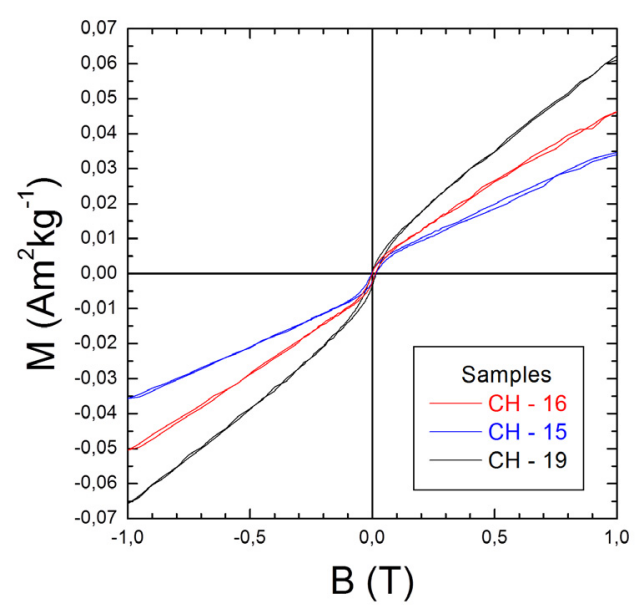

Figure 2. Hysteresis cycles for representative samples. Two main groups are individuated according to their magnetic behavior: presence of SD and PSD plus minor superparamagnetic grains (left side) and dominant paramagnetic grains plus faint SD and PSD contributions (right side). 

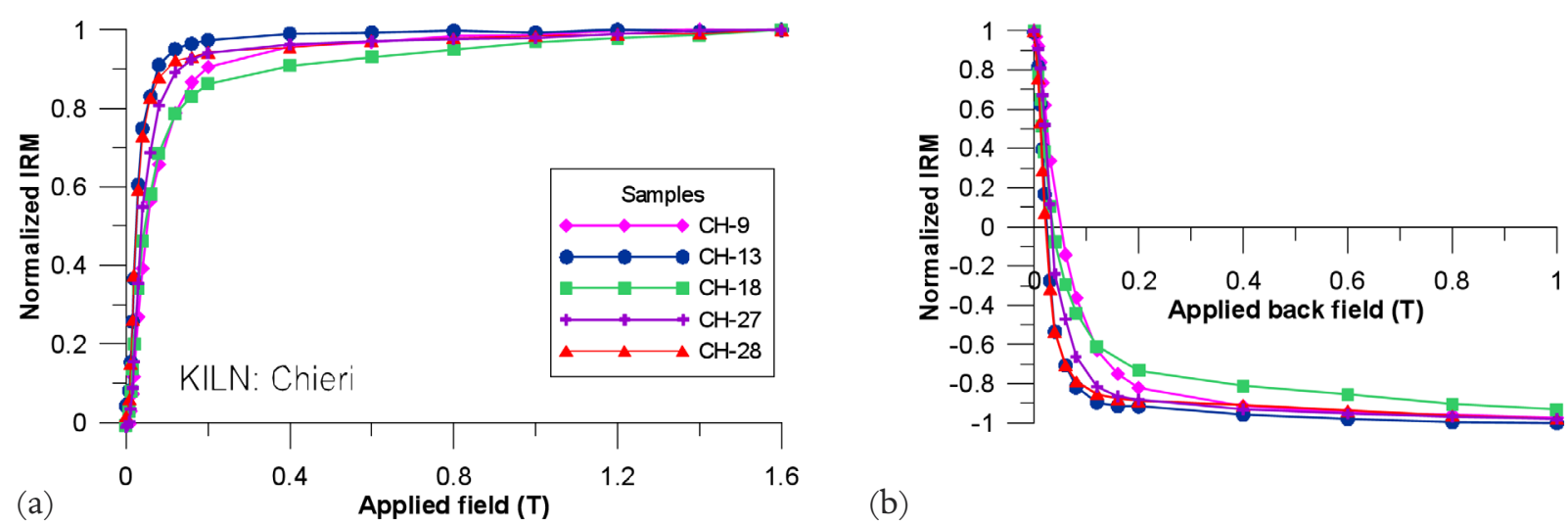

(b)

Figure 3. (a) Isothermal remanent magnetization (IRM) and (b) back field acquisition curves for representative samples.

netic particles (e.g. samples $\mathrm{CH}-15, \mathrm{CH}-16$ and $\mathrm{CH}-19$ ) together with a dominant paramagnetic contribution. In all cases, magnetic saturation is reached at about 0.5 $\mathrm{T}$ that is the field value at which magnetite-like minerals are expected to saturate.

The IRM acquisition curves for different samples show similar results to those obtained from hysteresis analyses, indicating that saturation is reached at fields around 0.4 to $0.6 \mathrm{~T}$ while only very few samples do not get completely saturated after $1.6 \mathrm{~T}$ peak field (e.g. sample $\mathrm{CH}-18$, Figure 3a). The application of a back field (Figure $3 \mathrm{~b}$ ) points to the dominance of a magnetic mineral of low remanent coercive force (around $50 \mathrm{mT}$ ). These results are also confirmed by the stepwise thermal demagnetization of composite IRM [Lowrie 1990] curves showing that most of the magnetization is carried by the magnetically soft fraction $(<0.1 \mathrm{~T})$ while the medium and high-coercivity components are generally very small (Figure 4). These results suggest the presence of magnetite and/or Ti-magnetite as the main magnetic carrier.

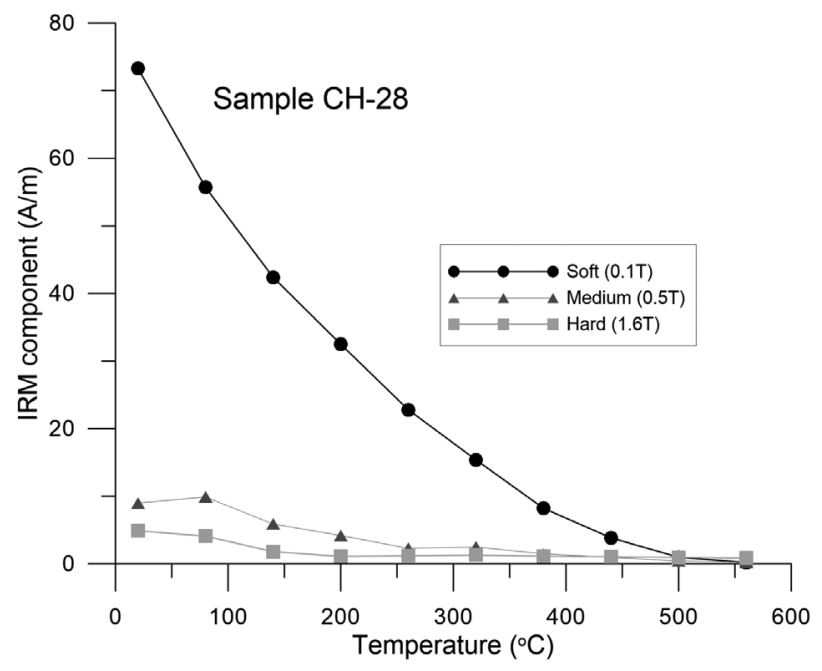

Figure 4. Stepwise thermal demagnetization of composite three axes IRM. Symbols: dot $=$ Soft- $(0.1 \mathrm{~T})$; triangle $=$ Medium- $(0.5 \mathrm{~T})$; square $=$ Hard $-(1.6 \mathrm{~T})$ coercivity component .

\subsection{Archaeomagnetic direction}

The natural remanent magnetization (NRM) of 26 cylindrical samples was measured using a JR-6 spinner magnetometer at the ALP palaeomagnetic laboratory (Peveragno, Italy). Subsequently, all samples were stepwise thermally demagnetized up to $580^{\circ} \mathrm{C}$ using a TSD-2 Schonstedt furnace. During demagnetization, 5 of the 26 samples were broken; therefore measurements were successfully completed on 21 samples. Demagnetization diagrams show that the magnetic remanence is stable and the characteristic remanent magnetization (ChRM) is clearly isolated for the majority of the samples (Figure 5a). Only 4 samples with disturbed and not lineal Zijderveld diagrams were rejected. In some samples, a secondary component of viscous origin was removed during thermal demagnetization.

The direction of the ChRM for each sample has been obtained from principal component analysis [ $\mathrm{Zi}$ jderveld 1967, Kirschvink 1980]. All directions at sample level are reported in Table 1, together with the Maximum Angular Deviation values (MAD) that for all the studied samples are lower than $5^{\circ}$. The mean direction for the kiln has been calculated according to Fisher statistics [Fisher 1953] based on 17 samples and it is: $\mathrm{D}=18.2^{\circ}$, $\mathrm{I}=66.8^{\circ}$ with $\alpha_{95}=2.6^{\circ}$ and $\mathrm{k}=184$ (Figure 5b).

\subsection{Archaeomagnetic dating results}

The mean kiln's direction has been used for archaeomagnetic dating after comparison with the reference SV curves calculated from the SCHA.DIF.3K regional geomagnetic field model [Pavón-Carrasco et al. 2009]. The reference curves have been directly calculated at the site geographical coordinates avoiding in this way any relocation error. Possible ages at 95\% confidence level have been calculated using the Matlab archaeo_dating tool [Pavón-Carrasco et al. 2011]. Taking into consideration the stratigraphy of the site which reasonably excludes that the kiln could be older than roman times, the possible dating intervals have been calculated only for the last 2000 years. The final 

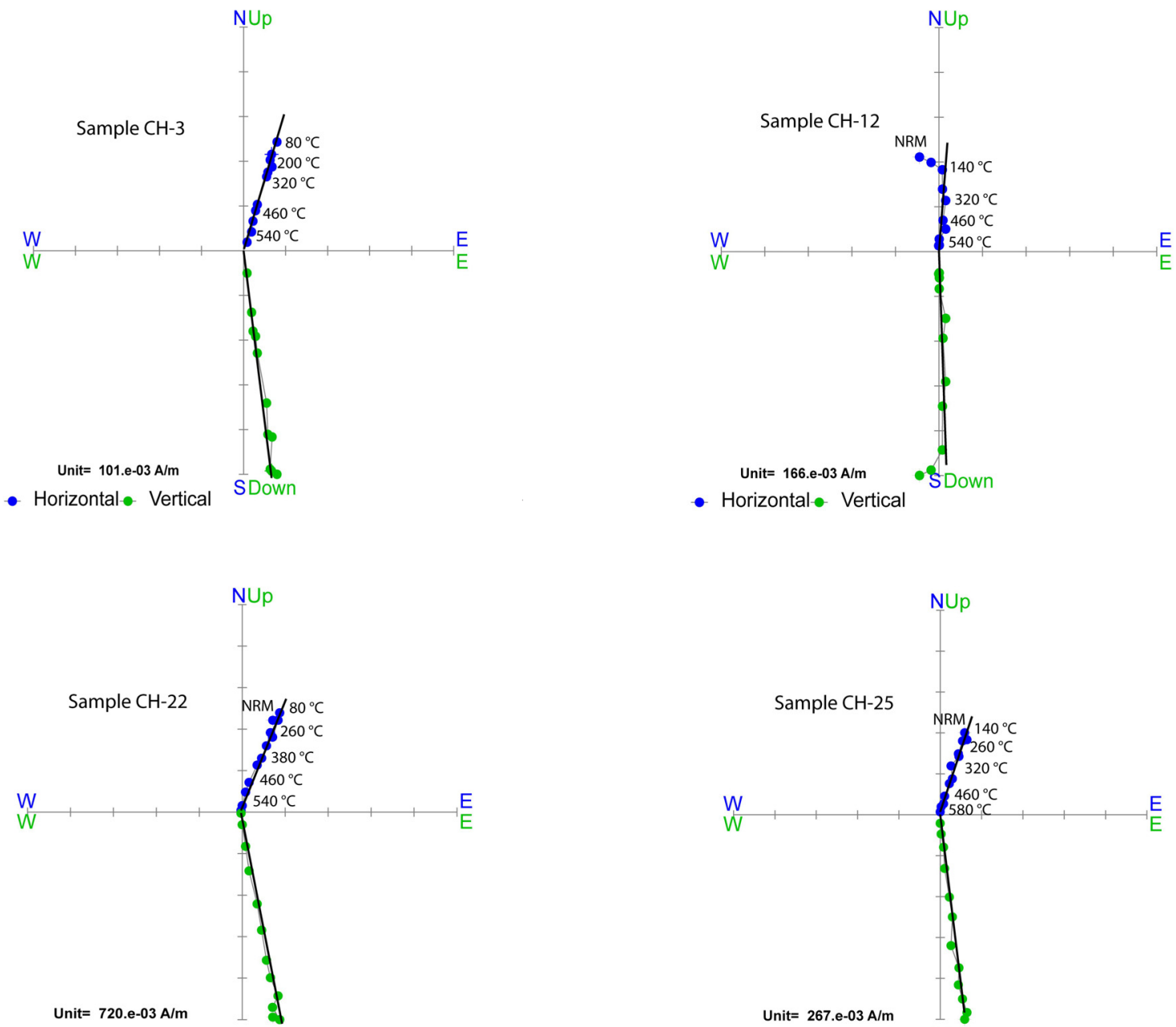

(a)

(b)

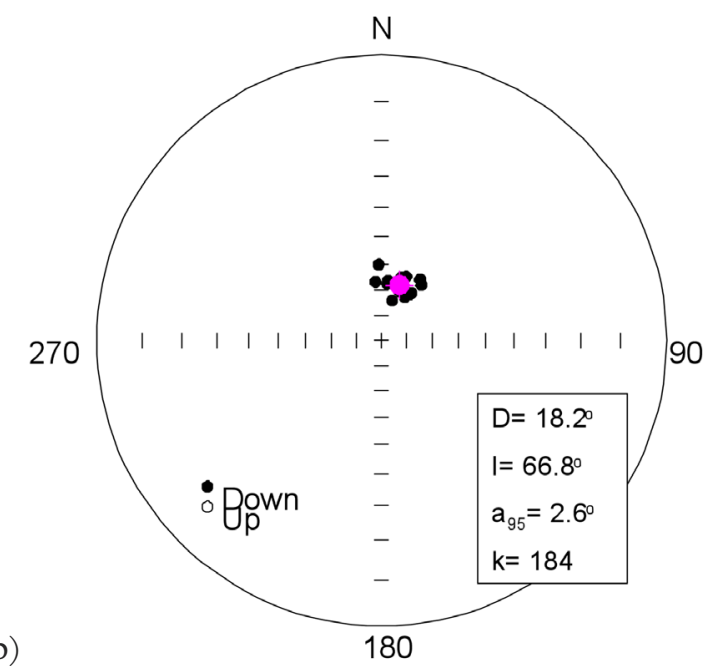

Figure 5 (top and above). (a) Stepwise thermal demagnetization results illustrated as Zijderveld diagrams for representative samples. Symbols: full dots = declination; open dots = apparent inclination; (b) Equal area projection of the ChRM directions at sample level together with the kiln's mean direction as calculated from Fisher statistics (pink dot).

Table 1 (right). Archaeomagnetic analysis results. Columns: Sample; Temperature interval used for the calculation of the direction of the ChRM at sample level; Declination $\left({ }^{\circ}\right)$; Inclination $\left({ }^{\circ}\right)$; MAD: Maximum Angular Deviation; Mean value: $\mathrm{N}=$ number of independently oriented samples; $\mathrm{D}_{\mathrm{m}}=$ mean declination; $\mathrm{I}_{\mathrm{m}}=$ mean inclination; $\mathrm{k}=$ precision parameter; $\alpha_{95}=95 \%$ semi-angle of confidence.
- Horizontal- Vertical

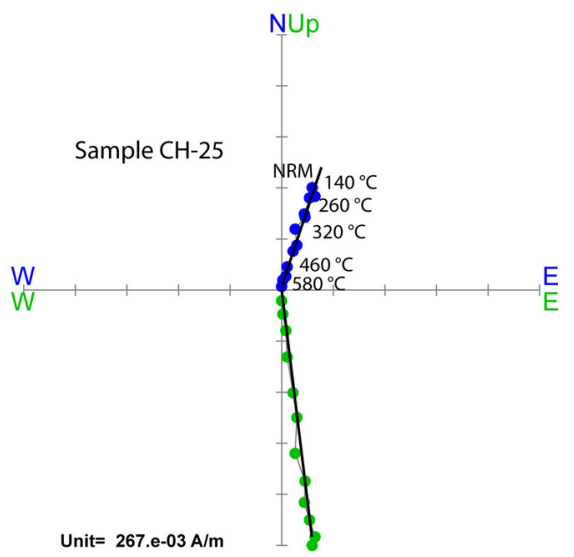

- Horizontab Vertical SDown

\begin{tabular}{|c|c|c|c|c|}
\hline Sample & $\begin{array}{l}\text { Temperature range } \\
\left({ }^{\circ} \mathrm{C}\right)\end{array}$ & $\begin{array}{l}\text { D } \\
\left({ }^{\circ}\right)\end{array}$ & $\begin{array}{c}\text { I } \\
\left({ }^{\circ}\right)\end{array}$ & MAD \\
\hline $\mathrm{CH}-3$ & $80-580$ & 17.4 & 64.0 & 3.4 \\
\hline $\mathrm{CH}-4$ & $200-580$ & 6.2 & 66.3 & 2.6 \\
\hline $\mathrm{CH}-5$ & $320-540$ & 19.3 & 69.2 & 0.7 \\
\hline $\mathrm{CH}-6$ & $320-540$ & 354.2 & 66.7 & 2.1 \\
\hline $\mathrm{CH}-7$ & $260-500$ & 12.6 & 67.2 & 1.5 \\
\hline $\mathrm{CH}-10$ & $320-500$ & 32.1 & 68.4 & 2.5 \\
\hline $\mathrm{CH}-12$ & $260-580$ & 5.8 & 67.5 & 2.5 \\
\hline $\mathrm{CH}-14$ & $320-500$ & 15.1 & 73.5 & 1.4 \\
\hline $\mathrm{CH}-15$ & $260-460$ & 32.1 & 67.8 & 1.1 \\
\hline $\mathrm{CH}-18$ & $380-500$ & 22.3 & 67.2 & 2.9 \\
\hline $\mathrm{CH}-19$ & $320-500$ & 35.7 & 63.1 & 4.6 \\
\hline $\mathrm{CH}-21$ & $200-580$ & 20.2 & 63.7 & 4.7 \\
\hline $\mathrm{CH}-22$ & $200-580$ & 21.1 & 63.1 & 2.1 \\
\hline $\mathrm{CH}-23$ & $200-580$ & 28.4 & 70.3 & 3.2 \\
\hline $\mathrm{CH}-24$ & $260-580$ & 358.0 & 60.1 & 2.8 \\
\hline $\mathrm{CH}-25$ & $140-580$ & 16.9 & 68.2 & 1.8 \\
\hline $\mathrm{CH}-26$ & $80-500$ & 32.3 & 61.7 & 4.4 \\
\hline $\begin{array}{l}\text { Mean } \\
\text { value: }\end{array}$ & & & & \\
\hline $\mathrm{N}=17$ & $\mathrm{D}_{\mathrm{m}}=18.2^{\circ} \mathrm{I}_{\mathrm{m}}=66.8^{\circ}$ & $\mathrm{k}=184$ & $x_{95}=2.6^{\circ}$ & \\
\hline
\end{tabular}



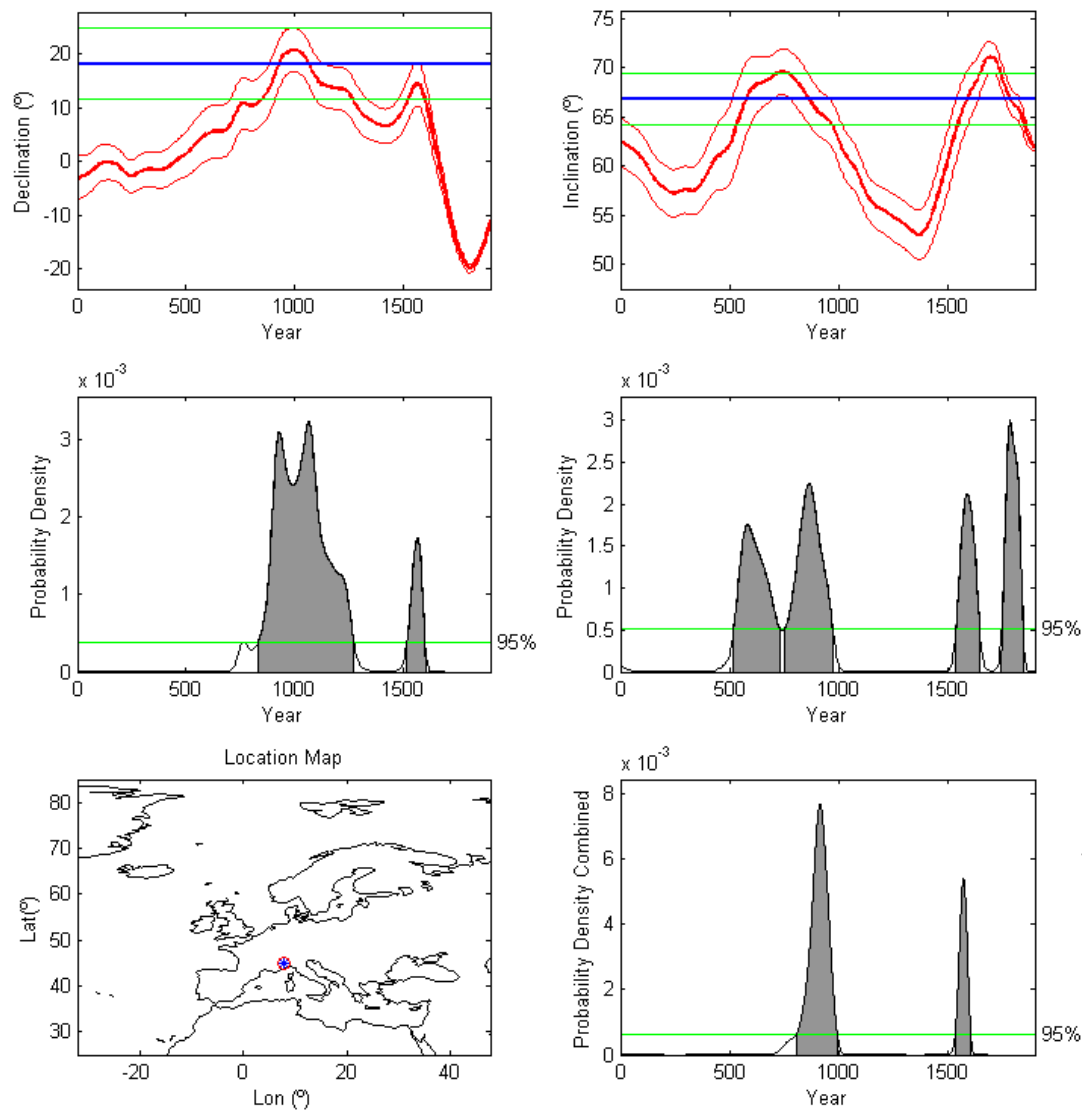

Dating : Chieri

Combining Probability Density Functions

Threshold $=0.00063808$ (Confidence $=95 \%$ )

Between $\mathrm{t}=\mathrm{OAD}$ and 1900AD

[808AD 994AD]

[1535AD 1606AD]

Figure 6. Archaeomagnetic dating results. Up: declination (left) and inclination (right) reference secular variation curves calculated from the SCHA.DIF.3K model (red curve with error band) and the kiln's measured direction (blue line with green error band); middle: calculated probability density functions for declination (left) and inclination (right); down: combined probability density function for declination and inclination.

dating of the kiln is obtained after the combination of the separate density functions for declination and inclination (Figure 6). Two possible dating intervals are proposed: a first one from 808 to $994 \mathrm{AD}$, and a second one from 1535 to 1606 AD. Combining the available archaeological evidence [Barello et al. 2013], the first time interval can be excluded suggesting that the kiln was abandoned around 1535-1606 AD at 95\% of confidence.

\section{Thermoluminescence dating}

Thermoluminescence (TL) dating has been performed at the Physics Department, University of Torino (Torino, Italy). Two baked clay cores (named TL1 and TL2), were drilled at the same place along with the collected archaeomagnetic samples and were used for TL analysis. The TL study was executed applying the fine grains method [Aitken 1985]. Due to the position of the analysed samples, coming from the internal wall of the kiln (Figure 1d), the calculated thermoluminescence age is related to the kiln's last use.

\subsection{Archaeological dose evaluation}

The two terms needed for the determination of the archaeological dose or palaeodose $(\mathrm{P})$ are: the equivalent dose (ED) and the supralinearity (I), a phe- nomenon that occurs at the initial history of the sample after its last firing for low irradiation doses [Aitken 1985]. In order to evaluate the archaeological dose, about $2 \mathrm{~g}$ of clay have been extracted from the two cores that present different color and high porosity and friability. The chemical procedure described by Vieillevigne et al. [2007] was applied for sample preparation. The ED was determined using the additive dose method for multiple aliquots [Fleming 1979] and a calibrated radioactive Sr-90 beta source was used to supply the artificial dose. After irradiation, pre-heating was performed in an oven at $150^{\circ} \mathrm{C}$ for $120 \mathrm{sec}$ to reduce the contribution to the TL signal coming from unstable traps. All thermoluminescence measurements were carried out by means of a TL2000-Ipses reader in nitrogen atmosphere using a $10^{\circ} \mathrm{C} / \mathrm{s}$ heating rate. The measured TL glow curves for sample TL 2 are shown in Figure 7. By means of the plateau test, the range $260^{\circ} \mathrm{C}-300^{\circ} \mathrm{C}$ was identified for integration and comparison of TL signals between natural and irradiated samples (for both cores). In Figure 8 the results and the linear fit for the ED calculation of TL2 sample are shown.

In order to measure the supralinearity, a second glow curve analysis at artificial irradiation doses was carried out after removing natural TL by means of a four-hour heating at $450^{\circ} \mathrm{C}$ [Aitken 1985]. 


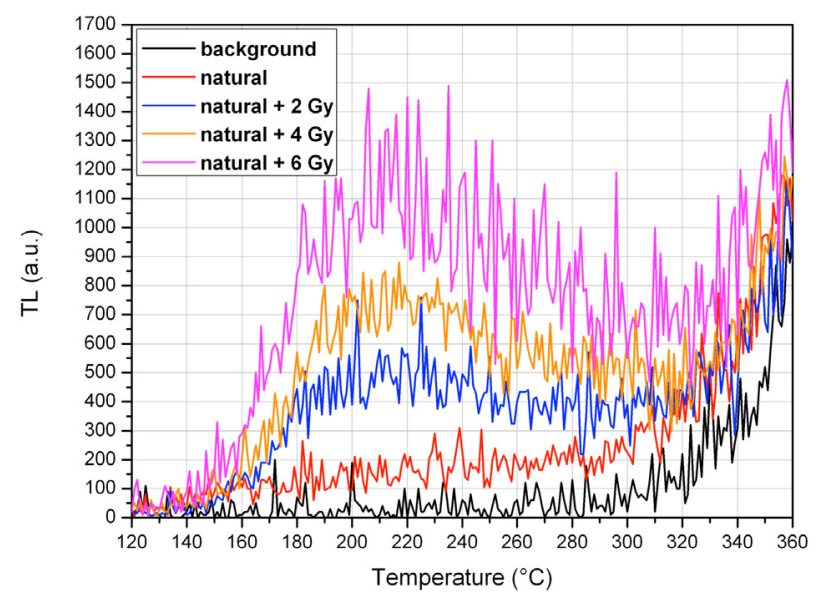

Figure 7. TL glow curves for sample TL 2. Beta irradiations were performed in the range $2 \mathrm{~Gy}-6$ Gy. For each irradiation two samples were prepared and measured.

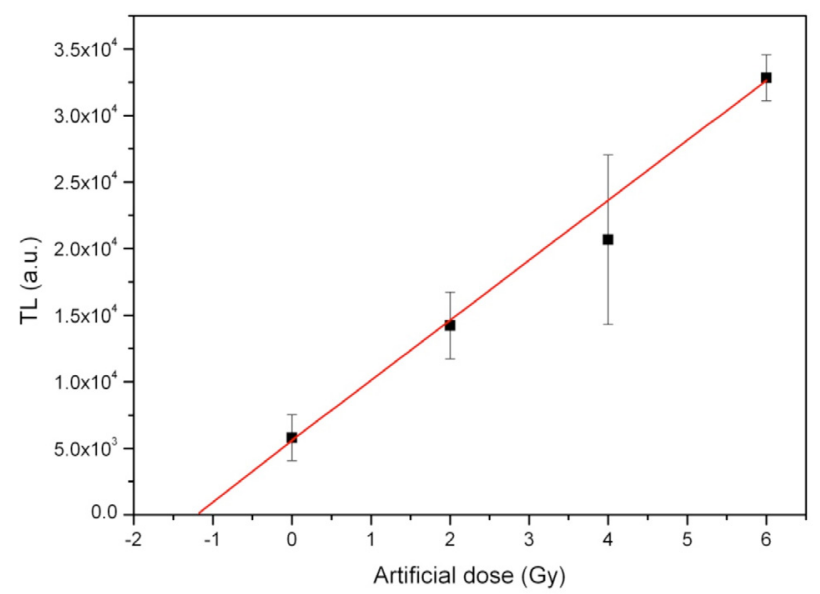

Figure 8. Linear fit for Equivalent Dose (ED) calculation for the TL 2 sample.

Finally, the anomalous fading was also estimated. Sample aliquots were irradiated with 6 Gy dose and stored in the dark at room temperature for 18 days together with other not irradiated aliquots. Then, the not irradiated aliquots were exposed to the same dose and their TL signal was compared with the TL of the previously irradiated ones. No anomalous fading was detected for the samples under investigation. All the results of ED, supralinearity I, and archaeological dose $\mathrm{P}$ for TL1 and TL2 samples are shown in Table 2.

\subsection{Annual dose evaluation}

The annual dose can be calculated as the sum of contributions from alpha, beta and gamma particles generated by radioactive decays. About $1 \mathrm{~g}$ of untreated clay from each core was employed to perform alpha decay counting by means of CALPH-Ipses apparatus. The measured radioactivity was utilized to calculate the annual dose due to alpha particles and also to evaluate the contribution to the activity from uranium and thorium decay chains. The alpha activity has to be corrected with the $\mathrm{k}$-factor [Aitken 1985], that is the 
efficiency of the alpha particles compared to beta particles in producing a TL signal, and it depends on the material. It was calculated comparing the $\mathrm{ED}$ values obtained respectively by means of alpha $\left({ }^{241} \mathrm{Am}\right.$ in vacuum) and beta particle artificial irradiations.

The measured alpha particle activity was also utilized to calculate the annual dose due to beta particles from uranium and thorium decay chains. The beta contribution of potassium to the annual dose was calculated after measuring its content in the baked clay samples by means of ICP-OES (Inductively Coupled Plasma-Optical Emission Spectroscopy) at Chemistry Department, University of Torino by considering the isotopic abundance of the ${ }^{40} \mathrm{~K}$ isotope. The measurement of the environmental dose in situ (gamma dose from the soil and cosmic radiation) has been performed with two series of LiF dosimeters, positioned and buried in proximity of the kiln's wall for a period of 90 days, before sampling. A value of $1210 \pm 150 \mu \mathrm{Gy} /$ year was estimated.

Finally, the annual dose contributions for each sample were corrected for the water content; the saturation content $(\mathrm{W})$ has been evaluated by means of a Sartorius MA35M thermobalance; the fraction of saturation was arbitrarily considered $\mathrm{F}=(80 \pm 20) \%$ [Aitken 1985]. Radon escape is supposed to be absent. All the results on annual dose have been calculated using doserate conversion factors [Guérin 2011] and are summarized in Table 2.

\subsection{Thermoluminesce dating results}

Considering all the measurements described above, the age of the last heating of the kiln has been calculated. Sample TL1 is dated $1690 \pm 25$ AD and sample TL2 is dated $1640 \pm 40 \mathrm{AD}$ (Table 2). Due to the macroscopic differences between the two cores and the impossibility to verify the absence of radon escape and anomalous fading for long periods, the expanded uncertainty was adopted to establish the range of possible ages, considering a 95\% confidence level (2-sigma) for each measurement. Therefore, the proposed thermoluminescence dating interval for the last firing of the kiln is $1560-1740 \mathrm{AD}$. This is in good agreement with the archaeological evidence and coincides with the second dating interval obtained by the archaeomagnetic analysis.

\section{Discussion and conclusions}

In this study, a multi-disciplinary approach has been applied for dating a rescue excavation kiln discovered at Chieri, combining archaeological, archaeomagnetic and thermoluminescence analysis. From archaeomagnetic dating, two possible dating intervals (808-994 AD

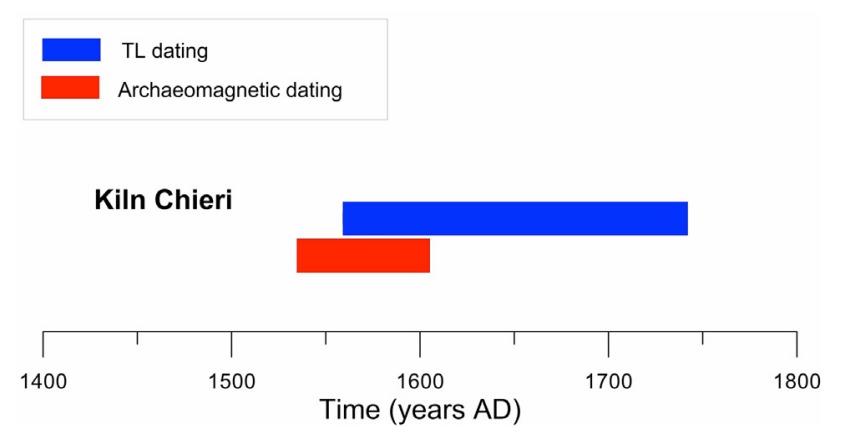

Figure 9. Archaeomagnetic and thermoluminescence dating results of the kiln excavated at Chieri.

and 1535-1606 AD) are proposed; when archaeological evidences are taken into account, the first of the two ages can be excluded, thus suggesting that the kiln was for last time used in 1535-1606 AD. Furthermore, the TL results suggest that the last firing of the kiln occurred around 1560-1740 AD. Both archaeomagnetic and TL results are consistent (Figure 9) and in accordance with the archaeological information available for the site, suggesting that most probably the kiln was abandoned at the beginning of the 17th century (even though TL results do not exclude its use up to $1740 \mathrm{AD}$ ). This study confirms that both archaeomagnetic and thermoluminescence techniques can be successfully applied on baked clay archaeological structures [Becker et al. 1994, Schnepp et al. 2003, Tema et al. 2013]. However, at the same time it shows that different dating techniques, even when applied to the same material, can give somewhat different results. This suggests that a cross-checking of dating methods is necessary for precise dating of an archaeological site.

Considering that the largest part of rescue excavations get destroyed in a short time after their discovery, this study also aims to encourage the collaboration between archaeologists and physics scientists in order to obtain the maximum number of information from a rescue archaeological site before it gets destroyed. Even in the cases that financial support is not immediately available, the systematic collection of samples by specialists is still very important. A properly performed sampling campaign offers the possibility of preserving important material and makes possible performing further investigations in the future. In this way, precious information about our cultural heritage, often preserved underground for thousands of years, will not get permanently lost even when the archaeological structures themselves could not be preserved.

Acknowledgements. The archaeologist Valentina Cabiale (FT Studio) is sincerely acknowledged for her help during sampling, for the planimetry of the site, and for fruitful discussion on the archaeological findings. 


\section{References}

Aitken, M.J. (1985). Thermoluminescence Dating, London Academic Press, 359 pp.

Barello, F., V. Cabiale, E. Ferrara, M. Girardi, E. Tema and S. Vella (2013). Chieri, via dei Molini n. 4: Resti di età romana e fornace postmedievale, Quaderni della Soprintendenza Archeologica del Piemonte, 28, 256-259 (in Italian).

Becker, H., H.Y. Göksu and D.F. Regulla (1994). Combination of archaeomagnetism and thermoluminescence for precision dating, Quaternary Sci. Rev., 13, 563-567.

Fisher, R.A. (1953). Dispersion on a sphere, Proc. R. Soc. Lond. A, 217 (1130), 295-305.

Fleming, S. (1979). Thermoluminescence Techniques in Archaeology, Clarendon Press.

Guérin, G., N. Mercier and G. Adamiec (2011). Doserate conversion factors: update, Ancient TL, 29, 5-8.

Kirschvink, J.L. (1980). The least-square line and plane and the analysis of palaeomagnetic data, Geophys. J. Astron. Soc., 62, 699-718.

Liritzis, I., and R. Thomas (1980). Palaeointensity and thermoluminescence measurements on Cretan kilns from 1300 to 2000 BC, Nature, 183, 54-55.

Lowrie, W. (1990). Identification of ferromagnetic minerals in a rock by coercivity and unblocking temperature properties, Geophys. Res. Lett., 17, 159-162.

Pantò, G., and L. Vaschetti (2010). Fornaci e ceramisti a Chieri fra XIII e XVI secolo, In: G. Pantò (ed.), Archeologia a Chieri. Da Carreum Potentia al Comune bassomedievale, Chieri, 123-129 (in Italian).

Pavón-Carrasco, F.J., M.L. Osete, J.M. Torta and L.R. Gaya-Piqué (2009). A regional archaeomagnetic model for Europe for the last 3000 years, SCHA.DIF.3K: applications to archaeomagnetic dating, Geochem. Geophys. Geosyst., 10 (3), Q03013; doi:10.1029/200 8GC002244.

Pavón-Carrasco, F.J., J. Rodriguez-Gonzalez, M.L. Osete and J. Torta (2011). A Matlab tool for ar-chaeomagnetic dating, J. Archeol. Sci., 38 (2), 408-419.

Schnepp, E., R. Pucher, C. Goedicke, A. Manzano, U. Müller and P. Lanos (2003). Paleomagnetic directions and thermoluminescence dating from a bread ovenfloor sequesnce in Lübeck (Germany): A record of 450 years of geomagnetic secular variation, J. Geophys. Res., 108 (B2), 2078; doi:10.1029/2002JB001975.

Spagnolo Garzoli, G., and V. Barberis (2012). Cerrione, località Magnonevolo. Fornace per laterizi di età postmedievale, Quaderni della Soprintendenza Archeologica del Piemonte, 27, 194-196 (in Italian).

Tema, E., F. Fantino, E. Ferrara, A. Lo Giudice, J. Morales, A. Goguitchaichvili, P. Camps, F. Barello and M. Gulmini (2013). Combined archaeomagnetic and thermoluminescence study of a brick kiln excavated at Fontanetto Po (Vercelli, Northern Italy), J. Archaeol. Sci., 40 (4), 2025-2035.

Vieillevigne, E., P. Guibert and F. Bechtel (2007). Luminescence chronology of the medieval citadel of Termez, Uzbekistan: TL dating of bricks masonries, J. Archeol. Sci., 34, 1402-1416.

Zijderveld, J. (1967). AC demagnetization of rocks: analysis of results, In: D. Collinson, K. Creer and S. Runcorn (eds.), Methods in Paleomagnetism, Elsevier, New York, 254-256.

\footnotetext{
${ }^{\star}$ Corresponding author: Evdokia Tema, Università di Torino, Dipartimento di Scienze della Terra, Torino, Italy; email: evdokia.tema@unito.it.
}

C 2014 by the Istituto Nazionale di Geofisica e Vulcanologia. All rights reserved. 